American Journal of Pharmaceutical Education 2018; 82 (8) Article 6409.

\title{
RESEARCH
}

\section{Predictors of Publication Rates for Abstracts Presented at the American Association of Colleges of Pharmacy Annual Meetings}

\author{
Samantha Spencer, PharmD, ${ }^{\mathrm{a}}$ Chloe Majkowski, PharmD, ${ }^{\mathrm{a}}$ Katie J. Suda, PharmD, MS ${ }^{\mathrm{a}, \mathrm{b}}$ \\ ${ }^{a}$ University of Illinois at Chicago College of Pharmacy, Chicago, Illinois \\ ${ }^{\mathrm{b}}$ Department of Veterans Affairs Center of Innovation for Complex Chronic Healthcare, Edward Hines, Jr. Veterans \\ Affairs Hospital, Hines, Illinois
}

Submitted March 17, 2017; accepted October 9, 2017; published October 2018.

Objective. To examine trends in manuscript publication rates for abstracts presented at the 2000, 2005, 2010, and 2015 American Association of Colleges of Pharmacy (AACP) annual meetings.

Methods. A systematic search of PubMed, Scopus, and Google Scholar was performed. "New" colleges and schools of pharmacy were defined as receiving accreditation after 1996. Contingency tables and $t$-tests were applied.

Results. There were 1382 abstracts evaluated. The overall publication rate was $20 \%$ and there was no difference in publication rates over 15 years. The median time to publication for years 2000, 2005, and 2010 was 15 months. The most frequent journal for publication was the American Journal of Pharmaceutical Education. The primary analysis identified several predictors for publication, including collaboration, presence of a $\mathrm{PhD}$ pharmaceutical program or academic medical center, and use of inferential statistics. There was no difference in manuscript publication when comparing "new" and legacy schools.

Conclusion. The publication rate of AACP abstracts has remained steady despite the increase in pharmacy schools and colleges and faculty. Collaboration among institutions was the strongest predictor for publication, highlighting its importance. The low publication rate observed may be attributed to a lack of training for junior faculty, insufficient forums to publish work, or misaligned motivations for scholarship among faculty. These barriers should be examined further.

Keywords: abstract, publication, AACP, research, conference

\section{INTRODUCTION}

Professional conferences provide a formal opportunity for conveying new ideas. Poster presentations are one platform that is used to deliver information about a research project; although the audience affected by the poster is often limited to conference attendees. Abstracts for poster presentations are published in conference proceedings, but full publication of research is necessary to reach a broader audience. Manuscripts provide more details on the methods and results of a research study, which is important to translating research into practice, reproducibility of the results, and strengthening validity through peer review. The abstract publication rates for pharmacy conferences have been examined previously. ${ }^{1-4}$ The publication rates have ranged from $10 \%$ to $33 \%$ at the American Society of Health-System Pharmacists (ASHP) midyear clinical

Corresponding Author: Katie J. Suda, College of Pharmacy, University of Illinois at Chicago, 833 South Wood St., 287 PHARM, Chicago, IL 60612. Tel: 312-996-3769. E-mail: ksuda@uic.edu meeting and American College of Clinical Pharmacy (ACCP) annual meeting, respectively. ${ }^{1}$ These rates are lower than the average publication rate for biomedical sciences reported in a 2007 systematic review. ${ }^{5}$ Furthermore for ASHP and ACCP meetings, the publication rate has not changed over time as a similar publication rate was seen in the 1994 meetings compared to the 2005 meetings. ${ }^{1,2}$

The American Association of Colleges of Pharmacy (AACP) hosts an annual meeting that accepts both educational and scientific research posters. The publication rate at this meeting is not known and the publication rate of educational research may differ from other areas of pharmacy research. Additionally, due to the rapid expansion of accredited pharmacy programs and increasing expectations for scholarship, a longitudinal evaluation provides insight on whether these factors affect the publication rate. Therefore, this study examined the publication rate of abstracts presented at the 2000, 2005, 2010, and 2015 AACP annual meetings. These time points were used to assess the effect of the number of pharmacy schools by framing the 


\section{American Journal of Pharmaceutical Education 2018; 82 (8) Article 6409.}

introduction of the mandatory PharmD program and the subsequent rapid expansion of the number of pharmacy schools. The number of accredited pharmacy programs in $2000,2005,2010$, and 2015 was $70,84,98$, and 125 , respectively. ${ }^{6}$ In addition to examining the publication rates, predictors for full publication were also evaluated.

\section{METHODS}

Abstracts were obtained from published abstracts in the American Journal of Pharmaceutical Education (AJPE) for 2000, 2005, 2010, and 2015 annual meetings. ${ }^{7-9} \mathrm{Ab}-$ stracts within the school poster category were not included in the analysis. For each abstract, the following data were collected: year of meeting, AACP section, number of authors, college or school of pharmacy of the primary author, presence of collaboration between multiple institutions, and statistics described in the abstract. Collaboration was determined based on whether there was more than one institution among the authors. Statistics were categorized into three categories: none present, descriptive statistics only, and use of inferential statistics.

PubMed, Scopus, and Google Scholar were systematically searched to determine if an abstract resulted in full publication. While there is overlap in the indexing of these databases, multiple databases were used to help identify journals that were only indexed in one of the databases. Scopus was selected for its more comprehensive coverage of education-related journals as compared to PubMed, CINAHL, Embase, and ERIC (an educational research database). ${ }^{10}$ Google Scholar was selected in order to use a different search methodology and capture any grey literature. The search was limited to the period of the meeting year through June 2017. The following sequence of search terms was used to locate publications: first author, second author, last author, iteration of the authors with keywords from the abstract title. For any publication that was identified as a potential full publication of the abstract, additional characteristics were reviewed to ensure that it was the same study presented at an AACP annual meeting. These characteristics included similar research question, study design, sample, and primary endpoints. For abstracts with a full publication, the journal name and date of publication were collected.

For the primary author's pharmacy school or college, additional characteristics about the institution were also collected. Data on year of accreditation was obtained from the Accreditation Council for Pharmacy Education website. "New" pharmacy schools and colleges were defined as receiving accreditation after 1996 based on previous research examining characteristics of "legacy" and "new" pharmacy schools and colleges. ${ }^{11}$ Presence of a $\mathrm{PhD}$ program was obtained from the AACP website. ${ }^{12}$ Academic medical center status was determined by examining the directory of the Association of Academic Health Centers. ${ }^{13}$

Based on likelihood that some abstracts from the 2015 meeting may eventually be published, the primary analysis for predictors of publication was completed using the 2000, 2005, and 2010 meeting years. A secondary analysis of all data, including 2015, was also completed. Statistical analyses were performed using R (Version 3.2.0 Vienna, Austria). Descriptive statistics were used to evaluate abstract characteristics and rate of full publication. Contingency tables and $t$-tests were used to evaluate whether certain characteristics impact the likelihood of publication. A $p<.05$ was considered statistically significant.

\section{RESULTS}

There were 1382 abstracts evaluated for the 2000, 2005, 2010, and 2015 AACP annual meetings. The overall publication rate was $20 \%$. There was no statistically significant difference in publication rates between the four meetings (Table 1). During 2000 to 2010, the median time to publication increased throughout the evaluation period, with an overall median time of publication of 15 months (interquartile range, 8 to 30 ), while the upper bound of the range time to publication decreased.

Table 1. Publication Rate and Time to Publication for Abstracts at the AACP Annual Meeting ${ }^{\mathrm{a}}$

\begin{tabular}{|c|c|c|c|c|}
\hline & \multicolumn{4}{|c|}{ Meeting Year } \\
\hline & 2000 & 2005 & 2010 & 2015 \\
\hline Number of abstracts & 259 & 174 & 524 & 425 \\
\hline $\begin{array}{l}\text { Time to publication, median (IQR) } \\
\text { (months) }\end{array}$ & 12 (6 to 29$)$ & $15(9$ to 36$)$ & $16(9$ to 28$)$ & $12.5(8 \text { to } 18)^{\mathrm{c}}$ \\
\hline Range time to publication (months) ${ }^{\mathrm{b}}$ & -4 to 72 & -7 to 63 & -4 to 54 & -3 to $26^{\mathrm{c}}$ \\
\hline
\end{tabular}




\section{American Journal of Pharmaceutical Education 2018; 82 (8) Article 6409.}

For all abstracts resulting in full publication, the majority were published in AJPE (Table 2). Currents in Pharmacy Teaching and Learning (CPTL) was the second most frequent location for full publications. The proportion of full publications indexed in PubMed, Scopus, and Google Scholar were $65 \%, 88 \%$, and $99 \%$, respectively.

Several predictors for publication were identified in the primary analysis of the 2000, 2005, and 2010 data (Table 3). Collaboration between multiple pharmacy schools and colleges was the strongest predictor, associated with two-fold increased odds of publication. The secondary analysis (including 2015) was consistent with the results of the primary analysis apart from the public or private status of the primary author's institution and the number of authors. With the addition of the 2015 data, authors from public institutions were more likely to publish their AACP abstract. During this 10year period, first authors with a "new" pharmacy school or college affiliation represented $20 \%$ of abstracts, increasing from $7 \%$ in 2000 to $30 \%$ in 2010 ( $p<.001$ for trend). However, affiliation with a "new" or legacy pharmacy school or college was not a significant predictor for likelihood of publication over the study period. Only one meeting year (2005) was associated with significant abstract publication differences where legacy schools were more likely to publish $(p=.035)$. Addition of 2015 data, of which $35 \%$ of abstracts represented "new" pharmacy schools and colleges, did not affect the likelihood of publication based on "new" or legacy status. Lastly, the AACP section that the abstract was submitted to was also not a predictor for likelihood of publication.

Table 2. Location of Full Publication of 2000, 2005, 2010, and 2015 AACP Abstracts

\begin{tabular}{lc}
\hline Journal & $\begin{array}{c}\text { Number of } \\
\text { Abstracts Published }\end{array}$ \\
\hline American Journal of Pharmaceutical & 144 \\
$\quad$ Education & 40 \\
$\begin{array}{l}\text { Currents in Pharmacy Teaching and } \\
\quad \text { Learning }\end{array}$ & 6 \\
American Journal of Health System & 6 \\
$\quad$ Pharmacy & \\
Journal of the American Pharmacists & 5 \\
$\quad$ Association & 5 \\
Pharmacy Practice & \\
Research in Social and Administrative & 5 \\
$\quad$ Pharmacy & 5 \\
Journal of Interprofessional Care & 3 \\
Pharmacy Education & 64 \\
Annals of Pharmacotherapy & 283 \\
Other & \\
Total &
\end{tabular}

\section{DISCUSSION}

This is the first assessment of publication from abstracts presented at AACP. Over the study period, the number of accredited pharmacy programs increased as well as the number of abstracts presented by faculty at new pharmacy schools and colleges. Despite this increase, the publication rate of AACP abstracts has not changed. This study identified the presence of collaboration as the strongest predictor for publication. This finding is consistent with previous literature evaluating pharmacy publication rates. ${ }^{14}$ Further, the result highlights the importance of mentoring junior faculty and seeking content experts to collaborate with to examine research questions. This is important considering the higher proportion of junior faculty members at "new" pharmacy schools and colleges and their potential lack of training and confidence in research methods. ${ }^{15,16}$

The publication rate of abstracts presented at the AACP annual meetings is similar to other pharmacy conferences (Table 4). ${ }^{1-4}$ The AACP publication rate was higher than ASHP, but it was lower than ACCP. While the audience of these three conferences may overlap, there are likely more academicians at AACP where scholarly activity is encouraged and required for promotion. In addition, the ASHP audience is likely to have more trainees and practitioners who may have less time or experience to write manuscripts. However, it is intriguing that ACCP has a higher publication rate than AACP. This may be secondary to a high number of clinical pharmacy researchers in attendance and availability of a long-standing research award at ACCP. Further, it may be attributed to the higher percentage of articles related to educational research presented at AACP, which may be of interest to fewer journals as compared to scientific research.

While not addressed in this analysis, it is also worth noting that motivation could be a barrier in translating some of the abstracts into full publications. A previous AACP survey of faculty members found that only $32 \%$ thought that scholarship should be required for promotion. ${ }^{17}$ Further, it has been noted that a small percentage of faculty are contributing to the majority of publications. An evaluation of experiential directors identified that $<1 \%$ of the cohort produced $35 \%$ of all works published between 2001 and 2012. ${ }^{18}$ Similarly, an evaluation of literature published by pharmacy faculty members between 2001 and 2003 found that $2.1 \%$ of the cohort produced $30.6 \%$ of the scholarship. ${ }^{19}$

Factors associated with publication have previously been described. These include positive results, rigor of the study design, authors described as research-focused faculty (as compared to clinical), male gender, and funded 
American Journal of Pharmaceutical Education 2018; 82 (8) Article 6409.

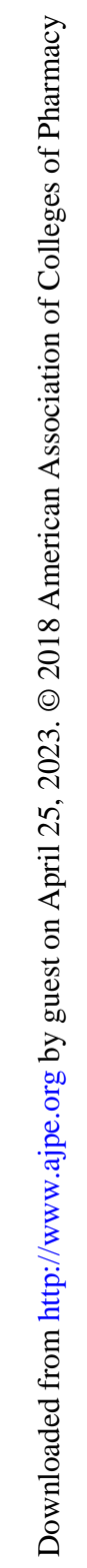

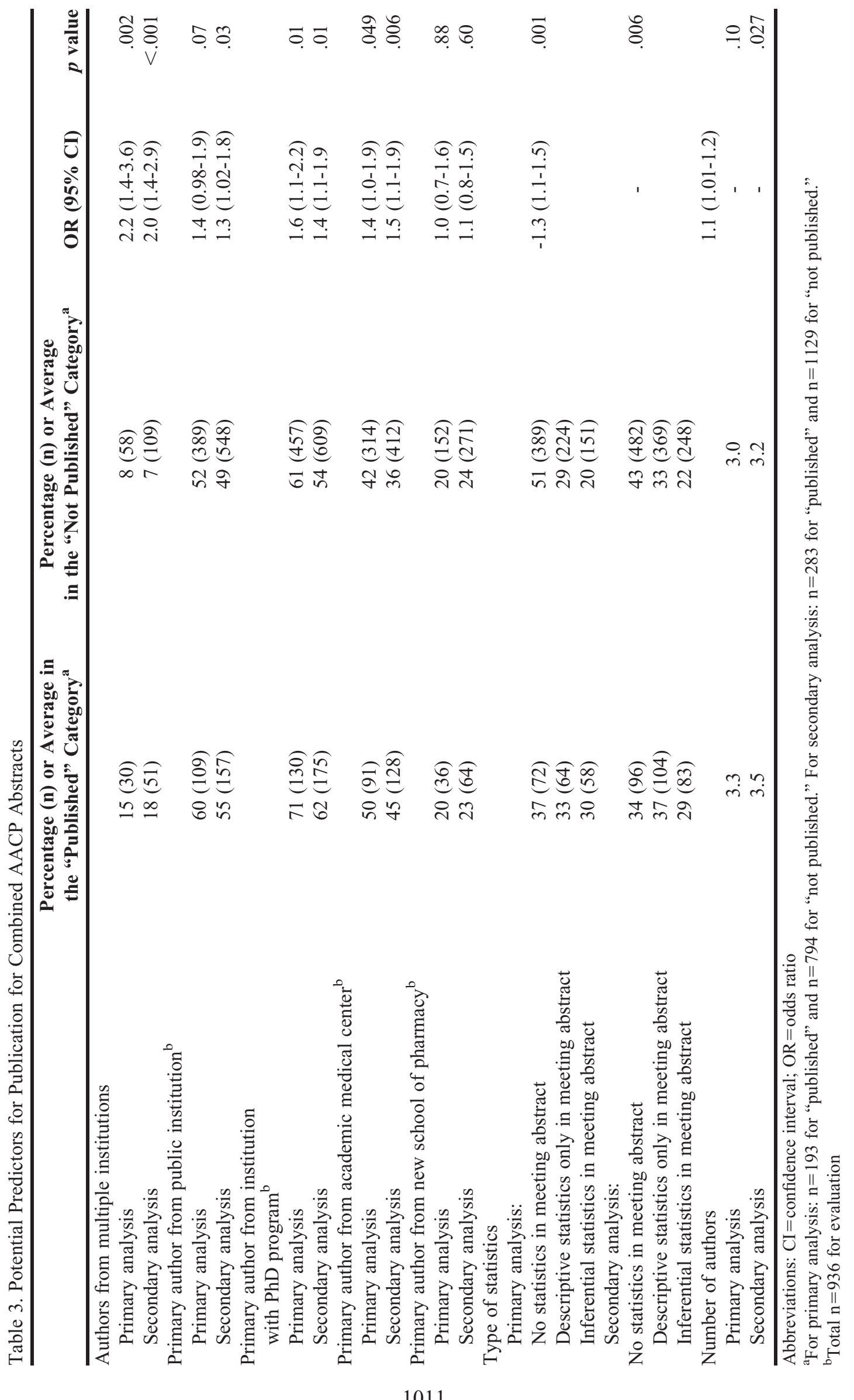




\section{American Journal of Pharmaceutical Education 2018; 82 (8) Article 6409.}

Table 4. Previous Literature Examining Publication Rates at Pharmacy Conferences, Excluding Residency Conferences ${ }^{1-4}$

\begin{tabular}{llc}
\hline & \multicolumn{1}{c}{ Conference } & Publication Rate (\%) \\
\hline Prohaska and colleagues & 2005 ACCP Annual Meeting & 33 \\
& 2005 ACCP Spring Meeting & 28 \\
& 2005 APhA Annual Meeting & 20 \\
& 2005 ASHP Summer Meeting & 14 \\
2005 ASHP Midyear Clinical Meeting & 10 \\
Byerly and colleagues & 1994 ASHP Midyear Clinical Meeting & 11 \\
& 1994 ACCP Annual Meeting & 33 \\
Stolk and colleagues & 1995-1999 ICPE Meeting & 26 \\
Ensom and colleagues & 1992-1996 CSHP Meeting & 25 \\
\hline
\end{tabular}

Abbreviations: $\mathrm{ACCP}=$ American College of Clinical Pharmacy, APhA=American Pharmacists Association, ASHP=American Society of Health-System Pharmacists, CSHP=Canadian Society of Hospital Pharmacists, ICPE=International Conferences on Pharmacoepidemiology

research. ${ }^{5,20}$ However, it is unknown if the type of research is a predictor for publication. People conducting biomedical research may be more likely to have funding, be researchfocused faculty, and male. Therefore, educational research may be more likely to be conducted without funding, by clinical faculty, and females. However, reasons for the overall low publication rate and factors associated with publication should be further evaluated in subsequent work.

However, there are some potential limitations to our results. Full publication may not be captured if an author changed their last name since the abstract was published. Additionally, selected keywords from the title may have not captured all publications. However, a variety of methods were used to capture publications (using multiple authors' names, abstract title, etc) to reduce those concerns. Further, there is not necessarily a 1:1 ratio of an abstract to a full publication. Efforts were made to not double-count manuscripts, but the calculated publication rate could have led to an underestimation of the productivity of producing full manuscripts in cases where multiple abstracts contributed to one publication. It was identified that the upper range extended beyond five years for the 2000, 2005, and 2010 meetings. Thus, abstracts presented at the 2015 conference may not have sufficient time for publication at the point of data collection, which allows only limited conclusions to be drawn from the data collected for that meeting. Quality of research methods was also not assessed comprehensively. However, statistical analysis may be considered as an indicator of quality. In addition, faculty may choose to present their research at other scientific forums. Therefore, poster presentations at AACP likely do not reflect the overall research conducted at pharmacy schools and colleges.

\section{CONCLUSION}

Collaboration among institutions was the strongest predictor for publication suggesting that there should be an increased focus on identifying networks to connect faculty with similar research interests. Additionally, the volume of research in pharmacy education appears to exceed the opportunities for publication. There are only a few journals with a primary focus in pharmacy education, which are published infrequently (eg, AJPE is published 10 times a year, CPTL is published bimonthly). Additional forums should be provided to pharmacy education researchers to publish their scholarly activity. Lastly, motivations of faculty members presenting posters should be further studied to determine if whether they are attempting and failing to fully publish their work or if they are not attempting to publish at all.

\section{ACKNOWLEDGMENTS}

The statements, findings, conclusions, and views contained and expressed herein are those of the authors and do not necessarily represent the views of the U.S. government or the Department of Veterans Affairs.

\section{REFERENCES}

1. Prohaska E, Generali J, Zak K, Grauer D. Publication rates of abstracts presented at five national pharmacy association meetings. Hosp Pharm. 2013;48(3):219-226.

2. Byerly WG, Rheney CC, Connelly JF, Verzino KC. Publication rates of abstracts from two pharmacy meetings. Ann Pharmacother. 2000;34(10):1123-1127.

3. Stolk P, Egberts AC, Leufkens HG. Fate of abstracts presented at five International Conferences on Pharmacoepidemiology (ICPE): 1995-1999. Pharmacoepidemiol Drug Saf. 2002;11(2):105-111.

4. Ensom M, Walker S. From abstract to publication: what makes the grade? Can J Hosp Pharm. 1998;51(6):280-284.

5. Scherer RW, Langenberg P, von Elm E. Full publication of results initially presented in abstracts. Cochrane Database Syst Rev. 2007(2): MR000005.

6. Accreditation Council for Pharmacy Education. Preaccredited and accredited professional programs of colleges and schools of pharmacy. https://www.acpe-accredit.org/pharmd-programaccreditation/. Accessed June 9, 2017.

7. 101st Annual Meeting of the American Association of Colleges of Pharmacy, July 7-12, 2000, San Diego, California. Am J Pharm Educ. 2000;64(Suppl):S86-S133. 


\section{American Journal of Pharmaceutical Education 2018; 82 (8) Article 6409.}

8. 106th Annual Meeting of the American Association of Colleges of Pharmacy, July 9-13, 2005, Cincinnati, Ohio. Am J Pharm Educ. 2005;69(3):Article 60.

9. 111th Annual Meeting of the American Association of Colleges of Pharmacy, July 10-14, 2010, Seattle, Washington. Am J Pharm Educ. 2010;74(5):Article 96.

10. Poirier T, Behnen E. Where and how to search for evidence in the education literature: the WHEEL. Am J Pharm Educ. 2014;78(4): Article 70.

11. Knapp DA, Knapp DE. Attributes of colleges and schools of pharmacy in the United States. Am J Pharm Educ. 2009;73(5):Article 96. 12. American Association of Colleges of Pharmacy. Trend data. http://www.aacp.org/resources/research/institutionalresearch/Pages/ TrendData.aspx. Accessed July 19, 2017

13. Association of Academic Health Centers. Members. http://www. aahcdc.org/About/Members. Accessed July 22, 2015.

14. Morris CT, Hatton RC, Kimberlin CL. Factors associated with the publication of scholarly articles by pharmacists. Am J Health Syst Pharm. 2011;68(17):1640-1645.
15. Assemi M, Hudmon KS, Sowinski KM, Corelli RL. Educational background and academic rank of faculty members within US schools of pharmacy. Am J Pharm Educ. 2016;80(4):Article 61. 16. Lee KC, El-Ibiary SY, Hudmon KS. Evaluation of research training and productivity among junior pharmacy practice faculty in the United States. J Pharm Pract. 2010;23(6):553-559.

17. Robles JR, Youmans SL, Byrd DC, Polk RE. Perceived barriers to scholarship and research among pharmacy practice faculty: survey report from the AACP Scholarship/Research Faculty Development Task Force. Am J Pharm Educ. 2009;73(1):Article 17.

18. Danielson J, McElroy S. Quantifying published scholarly works of experiential education directors. Am J Pharm Educ. 2013;77(8):Article 167. 19. Coleman CI, Schlesselman LS, Lao E, White CM. Number and impact of published scholarly works by pharmacy practice faculty members at accredited US colleges and schools of pharmacy (20012003). Am J Pharm Educ. 2007;71(3):Article 44.

20. Jagsi R, Guancial EA, Worobey CC, et al. The "Gender Gap" in authorship of academic medical literature - a 35-year perspective. $N$ Engl J Med. 2006;355:281-287. 